\title{
Barriers to Counseling on Advance Directives Based on Counselors' Experiences: Focus Group Interviews
}

\author{
Yejin Kim, M.S.W., Shin Hye Yoo, M.D., Wonho Choi, R.N., Min Sun Kim, M.D.*, \\ Hye Yoon Park, M.D., Ph.D. ${ }^{\dagger}$ and Bhumsuk Keam, M.D., Ph.D. ${ }^{\dagger}$ \\ Center for Palliative Care and Clinical Ethics, Seoul National University Hospital, Departments of *Pediatrics, ${ }^{\dagger}$ Psychiatry, and \\ ${ }^{\ddagger}$ Internal Medicine, Seoul National University Hospital, Seoul, Korea
}

Purpose: In Korea, since the Act on Hospice and Palliative Care and Decisions on LifeSustaining Treatment for Patients at the End of Life was implemented in February 2018, advance directives (ADs) have become legally effective and should be documented after sufficient explanation by a registered counselor. However, little is known regarding the adequacy of current $\mathrm{AD}$ counseling. This qualitative study aimed to explore the barriers to AD counseling based on counselors' experiences. Methods: We conducted focus group interviews using purposive sampling. Seven counselors working at hospitals, community health institutions, and non-profit organizations participated in this study. They were asked about the challenges and problems they encountered during AD counseling. Results: Three themes emerged from this study; 1) issues regarding consistency in $\mathrm{AD}$ counseling, 2) issues regarding $\mathrm{AD}$ counselors' competency and work environment, and 3) issues regarding the adequacy of the service system. The interviewees stated that the lack of a manual for standardized service made AD counseling inconsistent. The limited competency and poor work environment of counselors were pointed out as major barriers. The interviewees also stated that a proper service system considering individual circumstances is absent. Conclusion: The goals of $\mathrm{AD}$ counseling should be clarified and guidance should be implemented for providing standardized services. Further efforts to enhance the competency of $\mathrm{AD}$ counselors and to improve their working conditions are needed. Establishing an integrated framework for an adequate service system is also essential to overcome systematic barriers to $\mathrm{AD}$ counseling.

Key Words: Advance directives, Advance care planning, Terminal care, Counselors
Received March 11, 2020

Revised June 15, 2020

Accepted June 17, 2020

\section{Correspondence to}

Shin Hye Yoo

ORCID:

https://orcid.org/0000-0001-7473-1082

E-mail:ifi1024@gmail.com

This study was funded by the Korea National Institute for Bioethics Policy (KoNIBP).

\section{INTRODUCTION}

Advance directives (ADs) refer to the documentation of medical interventions that one desires or refuses in situations where one cannot indicate one's preferences regarding medical interventions [1]. In South Korea, education on dying well has been provided since the 1990s, and beginning with the Korean
Initiative for Advance Directives in 2012, non-governmental organizations such as the Korea Movement for Advance Directives in 2013 and Hope Do Re Mi in 2015 started supporting the documentation of ADs as part of their campaigns [2,3]. After the Act on Hospice and Palliative Care and Decisions on Life-Sustaining Treatment for Patients at the End of Life (hereinafter referred to as the Act on Decisions on Life-

This is an Open Access article distributed under the terms of the Creative Commons Attribution Non-Commercial License (http://creativecommons.org/licenses/by-nc/4.0/) which permits unrestricted non-commercial use, distribution, and reproduction in any medium, provided the original work is properly cited. 
Sustaining Treatment) was implemented for patients in hospice and palliative care or in the last stages of their lives in February 2018, ADs have been legally defined as the documentation of preferences regarding life-sustaining treatments and hospice care by individuals over the age of 19 in preparation of the last stages of their lives [4]. As of December 2019, the cumulative number of ADs documented was 532,667. The average number of documentations per month increased rapidly from 10,418 in 2018 to 38,582 in 2019 [5]. It is expected that the documentation of ADs will continue to increase. According to the Act on Decisions on Life-Sustaining Treatment, when an $\mathrm{AD}$ is filled out, the individual must receive an adequate explanation and indicate that he or she understands six components, including the implementation process of life-sustaining treatments and decisions regarding the withdrawal of life-sustaining treatments; preparation, documentation, and storage of the $\mathrm{AD}$; and changes and withdrawals of the $\mathrm{AD}$ [6]. After the implementation of the Act, counselors who are stationed at official $\mathrm{AD}$ filing centers explain the legally required components and counsel individuals before they document ADs.

$\mathrm{ADs}$ are important since they legally protect individuals' right to decide the manner of their death according to their will [7] and allow individuals to make decisions regarding their death based on their value systems. Since an AD is not simple, administrative paperwork, but a process of informed consent based on a sufficient understanding that allows an individual' s decision to reflect his or her values, the meaning and process are both important [8,9]. For informed consent, a highly supportive process is necessary in order to confirm individuals' capacity for self-determination and autonomy, to provide sufficient and accurate information, and to check individuals' understanding before filling out the document [10].

According to the Act on Decisions on Life-Sustaining Treatment, it is currently stipulated that the registration center should provide appropriate explanation and counseling [6]. The Korea National Institute for Bioethics Policy (KoNIBP), which operates the National Agency for Management of LifeSustaining Treatment, also states that counseling is necessary. Counseling can be defined in various ways, but generally, it can be understood as care work that aims to achieve others' growth and change. It is a highly professional service activity that is accompanied by stress and nervousness from handling problems and conflicts that are fundamental for human beings [11]. However, the AD Counseling and Registration Center Manual provided by the KoNIBP defines AD counseling as explanation, education, and promotion of the Act on Decisions on Life-Sustaining Treatment for the public, rather than one-on-one explanations. The law does not define counseling. Therefore, the official definition of AD counseling does not reflect general concepts of counseling, and in the field, ambiguity exists between explanation and counseling. Moreover, in practice, counseling is provided independently by registration centers with varying characteristics. The non-profit organizations that previously provided counseling as part of the movement for ADs are continuing to provide counseling services after the introduction of the law. Different levels of counseling are being provided through the National Health Insurance Service, at some local health centers, and at other health centers. The requirements for $\mathrm{AD}$ counselors are limited to having officially registered and receiving a 2-hour training provided by the KoNIBP. Considering these circumstances, concerns have been raised regarding whether AD counseling is provided with sufficient quality to ensure that individuals have a good understanding of the relevant issues when filling out the document.

Therefore, this study sought to obtain insights into barriers to providing quality counseling for $\mathrm{AD}$ documentation based on the experiences of counselors who are directly providing $\mathrm{AD}$ counseling.

\section{METHODS}

\section{Study participants}

In order to identify barriers to providing high-quality $\mathrm{AD}$ counseling, this study conducted focus group interviews. Purposive sampling was conducted to identify study participants appropriate for the study aim. Study participants were practitioners who were in charge of $\mathrm{AD}$ counseling at the $\mathrm{Na}^{-}$ tional Health Insurance Service, local health centers, and nonprofit organizations. Since it has been 1 year and half since the implementation of the Act on Decisions on Life-Sustaining Treatment, those with at least 6 months of experience providing $\mathrm{AD}$ counseling were recruited from each institution. Age, 
sex, education, degree, counseling experience, institutional affiliation, and type of counseling were obtained from the participants. Among 12 potential participants, seven participated in the study.

\section{Data collection}

Two researchers conducted two 2-hour-long focus group interviews with the study participants in August 2019. The main interviewer had worked as a medical social worker for 7 years and as an AD practitioner for 1 year, had experience conducting group counseling, and held a master's degree in social work. The secondary interviewer was a nurse who had worked in an internal medicine intensive care unit for 8 years, had been an AD practitioner for a year and half, and was completing her master's in bioethics. The two interviewers played complementary roles during the interview. The main interviewer facilitated the interview, maintained the focus of the interview, and encouraged interactions among the study participants. The secondary interviewer managed the time, checked whether any topics had been neglected, and took notes on remarkable points from the participants' discussion.

Before the interviews, the two researchers reviewed the existing literature on $\mathrm{AD}$ counseling $[3,7]$ and selected questions that investigated the barriers and difficulties perceived by $\mathrm{AD}$ counselors regarding quality improvement of $\mathrm{AD}$ counseling from multiple perspectives (Table 1). The interview questions were structured in four sections: opening questions, transi- tion question, key questions, and the final question [12]. In order to avoid leading questions, open-ended, semi-structured questions were used. The opening questions asked participants about their affiliations, AD counseling experiences, and academic background, while the transition questions asked participants about the $\mathrm{AD}$ counseling they provided in terms of the counseling structure, including the type and duration of counseling, the content and function of the counseling, and the counseling methods they used that were focused on individuals' core values and attitudes. The key questions were: "What kind of $\mathrm{AD}$ counseling is required based on the counselors' experiences?", "What challenges do AD counselors face?", and "What is the role of an AD counselor?" The final question asked whether there were any additional difficulties that had not been discussed so far.

The interviews were conducted in a meeting room that enabled a focused conversation. Study participants were encouraged to speak freely and comfortably. Active interactions among participants were encouraged, but they were reminded to be respectful of each other. Other group rules included keeping the information shared in the interview confidential. In order to maintain focus in the interview, the study aim and the questions were shared at the beginning of the interview, and individual questions were asked to clarify any points that were unclear during the interview. Before the interview ended, it was checked whether each participant had anything else to say, and participants were thanked. With consent from the partici-

Table 1. Questionnaire Used in the Focus Group Interview.

\begin{tabular}{ll}
\hline Type of question & \multicolumn{1}{c}{ Detail } \\
\hline Introduction & Please introduce your workplace, related experience, academic background, etc. \\
Transition & What kind of AD counseling do you provide? (based on structure of counseling - type, time, and method of counseling -, \\
Key questions & What kind of AD counseling do you think is needed? (tell us about your experiences) \\
& - What do you think makes it meaningful? \\
& - What kind of AD counseling would you like to see in the future? \\
- What might be needed for that to happen? & Which challenges do you face as an AD counselor? (tell us about your experiences) \\
- What do you think is the root of the problem? \\
- How do you want it to improve? \\
- What do you need for improvement? \\
What do you think the role of an AD counselor is? \\
- What do you think is needed in order to fulfill the role of a good AD counselor? \\
What challenges were not covered today, but still exist in your workplace? \\
\hline
\end{tabular}

AD: advance directives. 
pants, the discussion was audio-recorded and transcribed, and in order to protect the personal information of study participants, the transcripts did not contain any identifying personal information.

\section{Data analysis}

A thematic analysis of the study data was conducted [13], in which the main themes were identified by reading the data with a focus on the barriers according to the study aim. The data were reviewed again based on the main themes, and related sub-themes were identified. Central ideas were then extracted. The researchers transcribed the audio-recordings of the focus group interviews immediately after the interviews and recorded observational notes. The researchers each reviewed the content of the focus group interviews, and when there were ambiguities in meaning or discrepancies in opinions, the researchers checked their notes to confirm what participants stated. In accordance with the analytical methods described by Morgan and Scannell [14], the transcripts were read repeatedly before being coded, and themes and categories were established by comparing and contrasting similar themes. In order to minimize researcher bias and increase the reliability of the data, the analysis was audited by an external auditor.

\section{Ethical considerations}

The researchers identified themselves to the participants before the interviews started, the aim of the study was described in the informed consent form, and participants were notified that they could discontinue participation whenever they wanted. Before participants signed the informed consent form, they received an explanation of the voluntary nature of the study procedures, including audio-recordings, confidentiality of the participants and the interview content, and the interviewing process, and it was clarified that there were no disadvantages of not participating. The participants received a small monetary token of appreciation for sharing their experiences and participating in the study. In order to ensure ethical conduct, this study was approved by the Seoul National University Hospital Clinical Research Institutional Review Board (approval number: H-1908-055-1054).

\section{Results}

\section{General characteristics of participants}

The average age of the participants was 49.7 years. Six of the seven participants were women, and one was a man. Three had a bachelor's degree, three had a master's degree, and one had a doctoral degree. Three had majored in nursing, one in social work, one in health administration, and one in finance, and 1 had double-majored in nursing and social work. The average duration of $\mathrm{AD}$ counseling experience was 20 months (range: 6 52 months). Three worked at a tertiary hospital, three at non-profit organizations, and one at a local health center. All participants provided individual counseling, and the three who worked at non-profit organizations also pro-

Table 2. Characteristics of Study Participants.

\begin{tabular}{|c|c|c|c|c|c|c|c|}
\hline ID & Age/Sex & $\begin{array}{l}\text { Educational } \\
\quad \text { level }\end{array}$ & Major & $\begin{array}{c}\text { Duration of } \\
\text { counseling } \\
\text { experience (mo) }\end{array}$ & Affiliation & Subject & Place of counseling \\
\hline A & 59/Female & Bachelor & Nursing & 8 & Tertiary hospital & Individual & Separate counseling room \\
\hline B & 35/Female & Master & Nursing & 6 & Tertiary hospital & Individual & Separate counseling room, ward \\
\hline C & 60/Female & Master & Nursing & 18 & Tertiary hospital & Individual & Separate counseling room \\
\hline D & 27/Female & Bachelor & $\begin{array}{l}\text { Health } \\
\text { administration }\end{array}$ & 18 & $\begin{array}{l}\text { Community healthcare } \\
\text { center }\end{array}$ & Individual & Counseling room \\
\hline E & 55/Female & Bachelor & Social welfare & 26 & Non-profit organization & Individual/group & $\begin{array}{l}\text { Separate counseling room, ward, } \\
\text { facility, home visit, group lecture }\end{array}$ \\
\hline $\mathrm{F}$ & 48/Female & Doctor & $\begin{array}{l}\text { Nursing and } \\
\text { social welfare }\end{array}$ & 52 & Non-profit organization & Individual/group & $\begin{array}{l}\text { Separate counseling room, facility, } \\
\text { home visit, group lecture }\end{array}$ \\
\hline G & 64/Male & Master & Business & 12 & Non-profit organization & Individual/group & $\begin{array}{l}\text { Separate counseling room, ward, } \\
\text { facility, home visit, group lecture }\end{array}$ \\
\hline
\end{tabular}


vided group education. All participants except for one conducted counseling in private counseling spaces, and depending on their affiliation, participants also provided counseling at hospitals, institutions, organizations, home visits, and group courses (Table 2).

\section{Main themes}

Three main themes, five categories, and 12 sub-categories were identified in this study (Table 3).

\section{1) Issues regarding consistency in $A D$ counseling}

(1) Different purposes of $\mathrm{AD}$ counseling on which $\mathrm{AD}$ counselors focus

(1) Counseling focused on providing accurate information and supporting completion of the documents

In order for individuals to complete an $\mathrm{AD}$, it is necessary that they receive an explanation on the legally required information so that they have an accurate understanding of lifesustaining treatment. In that regard, the main purpose of $\mathrm{AD}$ counseling is to diligently deliver accurate information, to correct any misunderstandings about life-sustaining treatments or policies, and ultimately to help with the completion of the documents. Some participants stated that the current process of counseling was more education than counseling. In reality, many counselors only aim to ensure completion of the documents, and in such cases, problems such as individuals completing the documents without sufficient understanding can occur.

People have a lot of misunderstandings. [They think] "If I' $m$ sick or unconscious, I don't have to do anything." "The law is that way." People even think the time to death is months or a year. We need to point out where the law is different from commonly held beliefs. After counseling, people say "wow, it is so different from what I thought." (A)

After people understand the explanation, when they agree, the document is completed. For proper counseling, you need to enter into a person's heart, sympathize, and understand, but this [AD counseling] occurs in such a short time, so I don't think it is appropriate to call this "counseling." $(G)$

Recently, someone wanted to receive counseling about dying and to complete the document, so the person went to $O O$ registration center. The counselor told the person "I don't know about this. If you just complete the document, we just register it." I worry that people will think this is just a document they complete and submit. (E)

I feel that the purpose of counseling suggested by the KoNIBP and the purpose of counseling as we experience it are qualitatively different. ( $F)$

Table 3. Themes, Categories and Sub-categories Based on the Thematic Analysis of Counselors' Perspectives on Barriers to Advance Directives Counseling.

\begin{tabular}{|c|c|c|}
\hline Theme & Category & Subcategory \\
\hline $\begin{array}{l}\text { Issues regarding consistency } \\
\text { in } A D \text { counseling }\end{array}$ & $\begin{array}{l}\text { Different purposes of AD counseling on } \\
\text { which AD counselors focus }\end{array}$ & $\begin{array}{l}\text { Providing accurate information and supporting completion of documents } \\
\text { Providing opportunities for looking back on life and helping prepare for death } \\
\text { Finding and solving caregiving issues }\end{array}$ \\
\hline & Lack of manual for standardized services & $\begin{array}{l}\text { Variation in counseling by institution and individual counselors } \\
\text { Lack of specific guidance for counseling service }\end{array}$ \\
\hline $\begin{array}{l}\text { Issues regarding } \mathrm{AD} \\
\text { counselors' competency }\end{array}$ & $\begin{array}{l}\text { Counselors' self-perceived limitations of } \\
\text { competency }\end{array}$ & $\begin{array}{l}\text { Lack of knowledge } \\
\text { Lack of counseling skills }\end{array}$ \\
\hline and work environment & Poor work environment of AD counselors & $\begin{array}{l}\text { Counselors in non-profit organizations lack adequate acknowledgement and } \\
\text { compensation } \\
\text { Counselors in community healthcare centers experience structural difficulties } \\
\text { Counselors in hospital are burned out }\end{array}$ \\
\hline $\begin{array}{l}\text { Issues regarding an adequate } \\
\text { service system }\end{array}$ & $\begin{array}{l}\text { Lack of a proper service system } \\
\text { considering individual circumstances }\end{array}$ & $\begin{array}{l}\text { Limited visiting counseling services } \\
\text { Lack of a standard guideline for the proper distribution of limited resources tailored } \\
\text { to individual circumstances }\end{array}$ \\
\hline
\end{tabular}

AD: advance directives. 
(2) Counseling focused on providing opportunities for looking back on life and helping prepare for death

Participants reported that beyond completing the documents, they tried to facilitate self-reflection and retrospection among the elderly, help individuals think about what is best for them rather than for their family or others, and provide an opportunity to make proactive plans for their remaining lifetime. Moreover, counselors helped individuals to think more concretely about death, rather than continuing to consider death on an abstract level, and assisted them in making arrangements for end-of-life care accordingly.

I always counsel with these things in mind: helping people to organize their thoughts on the life so far and start thinking about how to plan to end their lives proactively, meaningfully, and with worth. I ask, "what percent of you thinks about yourself?" And they say, "me?" And only at that moment they realize how important it is to think about themselves. (C)

Retrospection and self-reflection are very necessary for the elderly, and discussions on life-sustaining treatment follow naturally. (F)

What we focus on is end-of-life care. Completing the form is not important. We need to think now about what end-oflife care will be like. (F)

I ask them to think about how they will meet death and how they will prepare for death with their family. Then they can think about the details, like whether they should go to the hospital or emergency room. (A)

(3) Counseling focused on finding and solving current caregiving issues

The participants reported that in the process of discussing end-of-life care, they often identified ongoing care issues facing individuals. In particular, when participants conducted home visits, they witnessed care issues in real life, so when they counseled individuals, they focused on solving these issues. In some cases, participants provided services directly or referred individuals to appropriate services.
An elderly person taking care of a disabled son, or an elderly person taking care of another elderly person. No care was there from the system, and families were left with the entire care burden. One time, someone told me "I am over 80 years old, and my wife has been bedridden for 20 years. I feel like I will die from taking care of her." I tend to focus on how I can help people in that kind of situation. (F)

When I go and see that their house is like a cave, that they have no beds-how difficult is that for terminal cancer patients? They are really neglected. I give them a foot massage and connect them to services they can use at centers. (E)

\section{(2) Lack of a manual for standardized counseling service provision}

(1) Variations in counseling across institutions and individual counselors

Participants pointed out that the content, method, and depth of counseling varied in current practice, and that the variation was particularly large across different counselors and registration centers. They suggested that reducing these discrepancies and providing standardized counseling services would be very important.

People would come to me and say, "Someone I know completed the form at $O O$ registration center and got it done within a few minutes." The first thing they ask is "let's make it fast." (A)

At $O O$ registration center, an administrative staff member does the counseling. Most counselors do not explain anything, but instead give people papers and pamphlets and say, "read it on your own and ask questions." They just say, "you will do it, right? It's a good thing." (F)

I do counseling for at least 40 minutes to an hour. After the counseling, people tell me "this was very different from what I thought. I'm glad I heard the explanations." I also give them materials with what I explained. (A)

Our non-governmental institution conducts visits to welfare centers, where we explain the issues to people in a group, and 
do it like that. (G)

(2) Lack of specific guidance for counseling services

The participants stated that specific guidance for standardized counseling service would be necessary to provide highquality counseling. Especially regarding judging the decisionmaking abilities of individuals and explaining each legally required item for $\mathrm{AD}$ counseling in a consistent manner, specific guidance is required, but is lacking. Some materials are provided by the KoNIBP for basic training for counselors, but in reality, each institution either develops and uses its own manual or does not use any materials. The participants voiced the opinion that standardized guidance should be prepared centrally to ensure the quality of counseling.

Because counseling styles are all different, everyone makes different manuals. I think there should be a standard when it comes to counseling content. It is necessary that wherever people go, the same content as to what life-sustaining treatment is and what death is needs to be provided. "You don't want a Levin tube? Then you should sign." That type of counseling should not happen. (C)

There needs to be some outline for counseling. It should be officially recognized that in order to provide basic explanation and counseling, a minimum of 30 minutes is required per person, and the explanation and counseling should occur together. This should be reflected when the government evaluates reimbursements. (A)

\section{2) Issues regarding AD counselors' competency and work environment}

(1) Counselor's self-perceived limitations of competency

(1) Lack of knowledge

$\mathrm{AD}$ counseling is a complex process that incorporates various elements, including the content of the Act on Decisions on Life-Sustaining Treatment, concepts of dying and life-sustaining treatment, and quality of life and self-determination. Thus, in order to help people understand, counselors should first have an accurate understanding of these concepts. However, participants reported feeling they did not have an adequate knowledge about concepts of dying and life-sustaining treat- ments, the decisions made about life-sustaining treatments in actual clinical practice, and the content and utilization of hospice care. Participants felt that the 2-hour-long basic training for $\mathrm{AD}$ counselors was insufficient to resolve the lack of knowledge. Some institutions run their own training sessions, but doing so is difficult for institutions that lack human and financial resources.

This type of counseling is particular. It's not like other counseling. We are providing limited, not in-depth, medical information. Since most counselors are not medical staff, it is true that we lack medical knowledge. (F)

Sufficient information should be given regarding hospice care and life-sustaining treatment so people can determine what is right for them, but they won't be able to understand if the counselor does not know or does not give that much of an explanation. (A)

What should actually be done if someone does not want life-sustaining treatment but the person cannot complete the $A D$ form? I heard that two family members should give statements, but I am curious how that process happens in actual clinical practice. (E)

There is a lot of demand for hospice education. I have to ask about their preferences, but I have to know something before I can ask. Even for counselors, the concept of hospice care is like a murky fog, so it is almost impossible for those who come in for counseling to understand. (F)

When my institution was running a training session, I asked to learn about the necessary documents, length of hospitalization, and the costs when patients go to hospice care. Because I get a lot of questions. (E)

\section{(2) Lack of counseling skills}

To provide high-quality counseling, counseling methods and techniques for efficient counseling (e.g., confidentiality and neutral attitudes as counselors) are necessary. However, due to the lack of counseling skills, counseling may be insufficient or manipulative if counselors have unethical attitudes or prioritize 
completion.

For example, conversational attitudes, conversational techniques, listening skills, and in some cases, you learn private information, so the responsibility to protect confidential information should be emphasized as well. You see some things during home visits, but you cannot gossip about what you see. You need to understand those principles, and you also need to know about basic counseling techniques in order to convey information and provide emotional empathy and proper listening. (C)

I listen to people who come for counseling. I have the concepts of re-statements and clarification in mind when someone repeats themselves over and over. But not all counselors can do that. (F)

I've seen counselors who measure their accomplishments by the number of ADs completed. They convince, appease, and are a bit forceful. They say things like, "Do you know how burdensome that is for your children, do you know how much they suffer" or "blood dialysis is a few hundred dollars, do you want to do it?" (C)

\section{(2) Poor work environment of $\mathrm{AD}$ counselors}

(1) Counselors at non-profit organizations lack adequate acknowledgement and compensation

Participants pointed out that the law does not mention counselors and does not take their role into consideration, so naturally there is no compensation or protection for counselors. At non-profit organizations, counselors work based on their own will and sense of duty, but there are difficulties financially and in terms of the structure of the organization. Moreover, since they are not publicly licensed, they feel that society has a negative impression of them as non-skilled workers, and since they cannot prove that they are qualified, it is hard for them to gain trust from people who come in for counseling. Participants also emphasized that there are no systems in place to protect counselors, especially during home visits.

In the law, there is no mention of the term "counselor." Who would do it if there is no guidance? Since there is no mention of counselors, of course there is no compensation. (F)

Counselors usually have a strong sense of duty and responsibility. However, it is very unfair. Because we are non-medical staff. Physician orders for life-sustaining treatment are covered by national insurance, but $A D$ is not. The annual compensation totals 20,000 to 30,000 dollars, not even enough for one person's salary. We use that money to pay for lunch for dozens of people. $(F)$

Being a senior citizen myself, I used my own money to voluntarily provide counseling from 3 years prior to the introduction of the law. Some institutions provide visiting counseling services and get reimbursed, but if that reimbursement did not exist, even if it's a voluntary service, I don't know if I could (provide visiting counseling services) using my own money. $(G)$

We made certificates for counselors independently. But because only our institution logo is on the certificate, people do not trust it, they say "what is this?" This problem remains even after I suggested [changes] multiple times. (E)

We do not send women due to the security issue. We heard that when female counselors went on home visits, there were some harassment incidents. So we don't send women anymore. Only men go. (G)

(2) Counselors at community healthcare centers experience structural difficulties

At local health centers, counselors felt overburdened since AD counseling was added to their normal workload. This was a temporary arrangement, but the situation did not improve. The physical environment was not adequate for counseling, and appropriate preparations were not made, leading to problems.

Since AD counseling was added to my workload, it has been a bit overwhelming, and the situation does not allow for sufficient counseling. It is becoming worse without improvements or support. (D)

The counseling room is used by the entire department. When 
there are lots of clients, people have to wait for a long time. The topic is very serious, but the space is open. We do not have tablet PCs, and everything is hand-written. So in some cases, we have to hold their hand so they can write. (D)

I was very surprised to learn how counseling is provided at other institutions and what equipment is used. At local health centers, it's rare to operate like that. We just feel exhausted, but we did not know what was lacking or where to bring our concerns. (D)

\section{(3) Counselors at hospitals experience burnout}

At hospitals, there are no designated counselors, so the work is distributed on top of the existing workload. As a result, the counselors experience excessive psychological and physical burdens. Moreover, when patients are referred to counseling by the medical staff, the discussion occurs too late. Therefore, counselors feel skeptical about helping patients to complete ADs when patients are in physical and emotional pain. The opinion was articulated that making dying patients complete ADs goes against the purpose of advanced care planning, which aims to think about the end of life beforehand.

For the past 6 months, I counseled 1,300 cases on my own. It's a tremendous amount of work. It takes at least $30 \mathrm{~min}-$ utes to counsel someone, but the schedule is so tight that I get depleted and experience difficulty reaching out in other areas. My voice is always lost. (B)

This law itself is about hearing these explanations when people have the lucidity and capacity to understand hospice and care, but if people are in a bad condition, they do not have time to understand or even hear about it. However, if they do not complete an $A D$, they will receive life-sustaining treatments. (A)

When an $A D$ is completed after a request from the doctor, it just gets completed as long as the patient has the strength to hold a pen. I wonder whether this aligns with the spirit of the law, whether this is really my role. (B)

It is a bit difficult for doctors to talk about physician orders for life-sustaining treatment. Patients are in the process of $d y-$ ing, and we have to go to them and we almost feel like we're trying to sell them something. I could not bring the words out. I feel very guilty about talking about not doing cardiopulmonary resuscitation, about not administering chemotherapy to those patients. (F)

\section{3) Issues regarding the adequacy of the service system}

(1) Lack of a proper service system considering individual circumstances

(1) Limited visiting counseling services

Participants stated that visiting counseling services are necessary for people who experience difficulties moving around, and anticipated that the demand for these services will increase. Currently, some non-profit organizations are providing visiting counseling services, but the supply is limited relative to the demand, so the barrier to use is very high.

The elderly directly come to the center for counseling, and we visit other institutions for education and counseling. Since February of this year, we have been providing visiting counseling to people in their homes. We started the program due to high demand this year. Because there aren't that many centers that provide visiting services $\cdots(F)$

I was in an underserved rural area, and there were 30 people with cerebral palsy who grew up in orphanages and now are living alone. They were all in their wheelchairs, desperate to complete this form. Whew. Their hands had become stiff due to their disability, so they were not able to sign. So, we ended up recording their voices and had to write in a lot of explanations. It was really difficult. (E)

\section{(2) Lack of standards and guidelines for the proper distribution of limited resources tailored to individual circumstances}

Currently, $\mathrm{AD}$ counseling is provided at registration centers, as visiting services, and in institutions, but participants pointed out that there is no system of providing individualized services. In particular, for visiting counseling services, not only is the provision of services lacking, but since there are no guidelines as to the selection and prioritization, the small amount of resources is being distributed inadequately, and operational 
problems exist. Participants also experienced difficulties due to the lack of a system to service populations that require specialized counseling, such as those with advanced diseases or rare and incurable diseases. Some participants voiced that the central government must make efforts to increase access and standardize services through local governments.

The fact that counselors visit home is very important. The eligibility or process of visiting counseling services should be publicized, but it is very difficult to rely on word-of-mouth. (A)

Those who used to work around US military bases are ostracized from society and discriminated against, so they live in groups. These people are now old and cannot move around. Those who live alone or do not have family members really are desperate to make decisions on life-sustaining treatment because of how the system is set up. We need to provide services to these groups first. $(F)$

As I provide visiting counseling services, I find that those who can move and those who can come in for counseling after a minor surgery request home visits. (E)

Everyone knows that it is so difficult for people with diseases like Lou Gehrig's disease. It is difficult for them to communicate and for us to discuss dying or life-sustaining treatment with them $\cdots(F)$

Even if you have the intention, it is not easy to visit registration centers. There should also be ways for working people to come in. (C)

I think that the public and private sectors need to network with each other more closely. There are areas that each can cover, so the public and private need to connect to form a network so that there are no blind spots. Information should be shared regarding regions, classes, and conditions that each can cover, so people know where to connect someone. (A)

\section{DISCUSSION}

ADs have great importance, as they are the product of people reflecting on their values regarding treatments in the dying process in preparation for when they will not be able to make decisions with sufficient informed consent $[15,16]$, they are therefore a solution to ethical conflicts that can occur when decisions about life-sustaining treatments are being made $[17,18]$. This study identified consistency in counseling, capacity, work conditions of counselors, and the service system as barriers to high-quality AD counseling, the aim of which is to help people to understand AD sufficiently.

The first theme regarded consistency. It was found that the focus of $\mathrm{AD}$ counseling differed among counselors and that counselors carried out diverse roles [19]. A reason for this may be the lack of a clear definition of AD counseling and its role, even though it can be inferred from the law that AD counseling should provide information about the required elements. Therefore, it is necessary to publicly clarity the core purpose and role of AD counseling [20]. Moreover, a consistent guideline on the specific process of counseling in accordance with its purpose is required. The AD Counseling and Registration Center Manual provided by the KoNIBP focuses on the information that counselors need to provide during counseling and the electronic record system that counselors need to use. Participants stated that the content is not detailed enough to use in real-world practice, and that the manual is inadequate as a guidance document for the actual conduct of counseling. In order to ensure the reliability of $\mathrm{AD}$ counseling, consistent information about core items and counseling services with a similar quality should be provided by all registration centers and counselors. To standardize services in this way, more specific and realistic guidelines, including how to judge individuals' decision-making ability [21], what to do when people do not understand the explanation in the manual, how specific the explanations of life-sustaining treatment should be in clinical settings where patients are dying, and when and how to explain hospice care, are necessary [16].

Second, AD counselors faced difficulties in terms of their own capacity and work environment. Counselors are professionals who determine the quality of the relationship with the individual receiving counseling, who lead the counseling pro- 
cess, and who serve as a therapeutic tool to help others [22], so the capacity of counselors is very important for the quality of counseling. Ideally, AD counselors should have adequate knowledge on advanced care planning and the laws and policies related to life-sustaining treatments, professional counseling techniques to facilitate value exploration and self-determination, educational tools to deliver accurate information, recognition of human rights, dignity, and self-determination, and ethical attitudes as counselors $[3,23]$. However, there are currently no official data on the capacity of counselors, and anyone can provide counseling once they complete a 2-hour basic training session on counseling. Counselors in the field feel they do not have sufficient capacity in terms of knowledge and counseling techniques. They reported that they especially lacked knowledge on how hospice care and the Act on Decisions on Life-Sustaining Treatment are implemented in actual clinical practice [10]. Moreover, participants reported that some counselors had problems in terms of their attitudes or ethics. The development of counselors' capacity in terms of knowledge and techniques is entrusted to each registration center, and guidelines are also developed and used by each center; thus, to improve the issue of capacity, ongoing realistic training and management seem to be necessary.

Moreover, counselors had issues pertaining to different types of registration centers in terms of the work environment [24]. Non-profit organizations employ volunteers and are experiencing difficulties finding financial support due to the lack of official recognition and compensation. There are no protection systems for them even though they are exposed to risks when they make home visits. Measures to support and protect them are urgently needed. Local health centers are close to community members and they have advantages in terms of their ability to identify vulnerable groups and to organically cooperate with other local government services, but the actual number of registrations is low. In this study, counselors at local health centers were found to be overburdened, and they stated that their physical environment was not conducive to counseling and that information-sharing was limited because they did not interact with other registration centers. Budgetary resources should be allocated to place adequate personnel at local health centers and to create an adequate environment for counseling. There should also be networking opportunities for registra- tion centers. At hospitals, there were difficulties in identifying personnel within the institution, so counselors had an excessive workload. They were often asked to take on doctors' responsibility to explain these issues to dying patients. Since the documentation was legally required for dying patients, counselors felt skeptical and depleted by the reality of asking patients in immense physical and psychological pain to complete ADs. The National Health Insurance System should provide motivation for hiring an adequate number of personnel by covering $\mathrm{AD}$ counseling, and discussions should be held about when $\mathrm{ADs}$ and provider orders for life-sustaining treatment documentation are completed and who should participate in those processes [25].

Regarding the appropriateness of the service system, which was the final theme, participants pointed out that the lack of visiting counseling services for those with mobility issues is a problem in the current $\mathrm{AD}$ counseling service system. People with mobility issues are neglected in discussions of lifesustaining treatment, since they also face limitations in visiting medical facilities [26]. Thus, it is necessary to plan to expand visiting counseling services for them [27]. Moreover, detailed strategies regarding the criteria needed for visiting counseling services to be utilized by those in most need of the services should be implemented. Visiting counseling services, which are rare, used to deal with requests from difficult clients, and in hospitals, despite the shortage of personnel, counseling was provided to outpatients; as a result, those with advanced diseases did not receive adequate medical explanations and completed ADs as a formality after administrative counseling. Other vulnerable populations, such as those in care facilities or those with no family, many not even get the chance to make a decision. The AD counseling system should be centralized so that the fragmented service system can be organized into a broader system, rather than each institution creating its own guidelines; by doing so, it should be possible for people who want to complete $\mathrm{AD}$ to receive adequate services according to their circumstances without being neglected.

The results of this study are limited to the seven participants, and since counselors from the National Health Insurance Service, which operates the greatest number of $\mathrm{AD}$ registration centers, were not included in the study, the generalizability of the study is limited. Therefore, additional research with a 
broader group of counselors might be required. Moreover, there is a scarcity of literature on $\mathrm{AD}$ counseling and $\mathrm{AD}$ counselors in South Korea and internationally, so it was not possible to adequately compare the results of this study to the existing literature. Further research is warranted.

Despite these limitations, this was the first study to demonstrate issues and aspects of quality improvement for $\mathrm{AD}$ counseling after the implementation of the Act on Decisions on Life-Sustaining Treatment. In order for ADs to protect selfdetermination, which is the goal of the Act, and to be implemented in clinical practice without confusion, high-quality counseling that facilitates sufficient understanding should be provided. The purpose of AD counseling should be clarified, specific guidance should be developed for standardized service provision, support should be provided for counselors' capacity-building, the work environment should be improved for each type of registration centers, and a central counseling service system should be established.

\section{ACKNOWLEDGMENTS}

We thank Ms. Jumi Koh, who provided insight and expertise that greatly assisted the study, and Mr. Soon Chan Hwang for guidance on the analysis of data.

\section{CONFLICT OF INTEREST}

No potential conflict of interest relevant to this article was reported.

\section{ORCID}

Yejin Kim, https://orcid.org/0000-0002-1479-3385

Shin Hye Yoo, https://orcid.org/0000-0001-7473-1082

Wonho Choi, https://orcid.org/0000-0002-7756-4491

Min Sun Kim, https://orcid.org/0000-0001-5323-9857

Hye Yoon Park, https://orcid.org/0000-0003-4114-5102

Bhumsuk Keam, https://orcid.org/0000-0001-8196-4247

\section{AUTHOR'S CONTRIBUTIONS}

Conceptualization: YK, SHY, WC. Data curation: YK, WC. Formal analysis: YK, WC, SHY. Funding acquisition: MSK. Investigation: YK, WC. Methodology: YK. Project administration: SHY. Resources: YK, WC. Supervision: HYP. Visualization: YK. Writing - original draft: YK, SHY. Writing review \& editing: YK, SHY, WC, MSK, HYP, BK.

\section{SUPPLEMENTARY MATERIALS}

Supplementary materials can be found via https://doi. org/10.14475/kjhpc.2020.23.3.126.

\section{REFERENCES}

1. Miller RB. Physician orders to supplement advance directives: rescuing patient autonomy. J Clin Ethics 2009;20:212-9.

2. Kim SM, Hong YS, Kim HS. Advance directives in Korea and other countries. Korean J Med Ethics 2010;13:193-204.

3. Lee $\mathrm{I}-\mathrm{H}$. Advance directives preparation and application: Survey on current activities of non-governmental advance directives organizations and policy recommendations. Seoul:Office of Research Affairs UIF Yonsei University;2016.

4. What is an advance drectives [Internet]. Seoul: National Agency for Management of Life-Sustaining Treatment; c2020 [cited 2020 Feb 27 ]. Available from: https://lst.go.kr/eng/medi/medicalintent.do.

5. Monthly statistics of advanced directives documentations [Internet]. Seoul: National Agency for Management of Life-Sustaining Treatment; c2020 [cited 2020 Feb 27]. Available from: https://www.Ist.go.kr/comm/monthlyStatistics.do.

6. Preparation, Registration, etc., of Advance Statements on Life-Sustaining Treatment [Internet]. Sejong: National Law Information Center; c1997-2020 [cited 2020 Feb 27]. Available from: http://www.law.go.kr/LSW/eng/engLsSc.do? menuld=2\&section=lawNm\&query=LIFESUSTAINING+TREATMENT\&x=0\&y=0\#liBgcolor0.

7. Joo J. A study on the activation plan of advance directives [master's thesis]. Seoul: Yonsei Univ.; 2016. Korean.

8. Keam B, Yun YH, Heo DS, Park BW, Cho CH, Kim S, et al. The attitudes of Korean cancer patients, family caregivers, oncologists, and members of the general public toward advance directives. Support Care Cancer 2013;21:1437-44. 
9. Kang KA, Lee KS, Park GW, Kim YH, Jang MJ, Lee E. Community dwellers' perception of past life recollection and preparation for death. Korean J Hosp Palliat Care 2011;14:81-90.

10. Beauchamp TL, Childress JF. Principles of biomedical ethics. 6th ed. Park CG, translator. Seoul:BOOKK;2017.

11. Oh HS, Han JH. Analysis on the experiences of overcoming frustration in developmental process of professional counselors. Korea Journal of Counseling 2009;10:109-24.

12. Krueger RA. Casey MA. Focus groups: a practical guide for applied research. Thousand Oaks:SAGE Publications, Inc;2014.

13. Braun V, Clarke V. Using thematic analysis in psychology. Qual Res Psychol 2006:3:77-101.

14. Morgan DL. Planning focus groups. Thousand Oaks, Calif.:SAGE Publications;c1998.

15. Silveira MJ, Kim SY, Langa KM. Advance directives and outcomes of surrogate decision making before death. N Engl J Med 2010;362:1211-8.

16. Kim S, Hong SW, Eun Y, Koh SJ. Prerequisite for Korean advance directives: from the view of healthcare providers. J Korean Acad Nurs 2012;42:486-95.

17. Scherer Y, Jezewski MA, Graves B, Wu YW, BuX. Advance directives and end-of-life decision making: survey of critical care nurses' knowledge, attitude, and experience. Crit Care Nurse 2006;26:30-40.

18. Karnik S, Kanekar A. Ethical issues surrounding end-of-life care: a narrative review. Healthcare (Basel) 2016;4:24.

19. donga.com [Internet]. Seoul: Dong-A Ilbo; 2019 [cited 2020 Feb 27]. Available from: https://www.donga.com/news/Society/article/ all/20190131/93954705/1.

20. Montanari Vergallo G. Advance healthcare directives: binding or informational value? Camb Q Healthc Ethics 2020;29:98-109.

21. Abu Snineh M, Camicioli R, Miyasaki JM. Decisional capacity for advanced care directives in Parkinson's disease with cognitive concerns. Parkinsonism Relat Disord 2017;39:77-9.

22. Kim YK. The dimensionality of clients' perceptions of counselor's factors as therapeutic factors. Korean Journal of Counseling and Psychotherapy 2013:25:203-26.

23. de Caprariis PJ, Rucker B, Lyon C. Discussing advance care planning and directives in the general population. South Med J 2017;110:563-8.

24. khan.co.kr [Internet]. Seoul: The Kyunghyang Shinmun; 2017 [cited 2020 Feb 27]. Available from: http://news.khan.co.kr/kh_news/khan_ art_view.html?art_id=201710231701001.

25. Teno JM. Advance directives: time to move on. Ann Intern Med 2004;141:159-60.

26. Song J, Ratner ER, Wall MM, Bartels DM, Ulvestad N, Petroskas D, et al. Effect of an End-of-Life Planning Intervention on the completion of advance directives in homeless persons: a randomized trial. Ann Intern Med 2010;153:76-84.

27. Schnakenberg R, Silies K, Berg A, Kirchner A, Langner H, Chuvayaran Y, et al. Study on advance care planning in care dependent communitydwelling older persons in Germany (STADPLAN): protocol of a cluster-randomised controlled trial. BMC Geriatr 2020;20:142. 